\section{Workplace urine screening for drug abuse}

SIR

Forrest's article on ethical aspects of workplace urine screening for drug abuse $^{1}$ is based largely on his assertions that drug screening is "an established part of occupational medical practice" involving a "definite doctor-patient relationship", and that the employee's rights are denied by not having access to his or her urine sample.

The Faculty of Occupational Medicine $^{2}$ has made clear that a drug-testing programme is a company programme in which medical staff act as agents. There is no doctor-patient relationship. The doctor (or, more frequently, the nurse) is necessarily involved to ensure that strict procedures are laid down and followed, and that the rights of the subject (who is not a patient) are protected. This will include obtaining proper informed consent and ensuring that the two samples are secured within a chain of custody which can withstand legal challenge.

The faculty also emphasises ${ }^{3}$ the need for using a laboratory with proven competence in all aspects of drug screening. It is common practice for an external specialised company to provide a complete package, running from collection of the sample to reporting the provisional results to the Medical Review Officer (MRO). The $\mathrm{MRO}$ is commonly an occupational physician, and the need for appropriate training has been emphasised by the faculty. It is widely available. The role of the MRO is to ensure that the provisional positive result reported by the laboratory is, beyond reasonable doubt, due to substance abuse, and not to medicines or other confounders, including those which Forrest describes. Most of these problems of false-positive reporting can be overcome quite simply by setting an appropriate cut-off point for positive reporting and obtaining a detailed history, including possible confounders, at the time of collection of the sample. A competent laboratory will be well aware of these pitfalls, and there is plenty of opportunity for discussion between the MRO and the laboratory. The MRO will normally see the subject with a provisional positive result. I can only imagine a telephone interview, which Forrest seems to imply is normal, when the subject, as is his right, declines to see the MRO.

If a result is positive, the subject can ask that the second sample be sent to a laboratory of his choice. This can be done within the legal chain of custody. If the subject himself were given a sample it would pass outside such a chain, and no one, including the subject, could demonstrate that it was his sample from that occasion. I have never heard of a subject being denied all access to the sample in the way suggested by Forrest, and such action would surely end up in court, as he indicates.

Forrest seems confused over the reporting procedures. As this is a management (not a medical) procedure, reporting is always to management. Part of the procedure when setting up the programme is to identify the named member of management to whom the report will go. The laboratory/screening company will report to the MRO. Only after that review will the report go to management - simply as a positive result. Negative results, the vast majority, are usually not reported.

As the whole procedure is not carried out in connection with the health care of the subject, the Access to Health Records Act ${ }^{4}$ and the Access to Medical Reports Act $^{5}$ do not apply. However, there is no question but that the subject has the result, and can challenge it. If Forrest has evidence of unlawful acts, no doubt he will bring it to the attention of the proper authorities. If employers are acting as he implies, with or without the assistance of health professionals, surely cases would have reached the courts. Employers involved in these procedures are generally well aware of the need for the whole programme to be most carefully planned, with full consultation, as otherwise it will not succeed.

Occupational physicians are extremely conscious of the ethical and practical pitfalls in testing for drugs of abuse in the workplace. While much in his paper is open to challenge, Forrest performs a valuable service by raising this issue and reminding all practitioners that this is not an area for any physician to enter without proper training and the ready access to experienced colleagues which is the basis for good ethical practice.

\section{References}

1 Forrest ARW. Ethical aspects of workplace urine screening for drug abuse. Fournal of Medical Ethics 1997; 23: 12-17.

2 Faculty of Occupational Medicine. Guidance on ethics for occupational physicians [4th ed]. London: Faculty of Occupational Medicine, 1993.

3 Faculty of Occupational Medicine. Guidelines on testing for drugs of abuse in the workplace. London: Faculty of Occupational Medicine, 1994.

4 Access to Health Records Act 1990.

5 Access to Medical Reports Act 1988.

DR D S WRIGHT, OBE, FRCP, FFOM Chairman, Ethics Committee, Faculty of Occupational Medicine of the Royal College of Physicians, 6 St Andrew's Place, Regent's Park, London NWI $1 L B$ 